\title{
The Case Fatality Rate in COVID-19 Patients With Cardiovascular Disease: Global Health Challenge and Paradigm in the Current Pandemic
}

\author{
Siddhartha Dan ${ }^{1} \cdot$ Mohit Pant $^{2} \cdot$ Sushil Kumar Upadhyay ${ }^{3}$ (D) \\ Accepted: 8 September 2020 / Published online: 15 September 2020 \\ (C) Springer Nature Switzerland AG 2020
}

\begin{abstract}
Purpose of Review Severe acute respiratory syndrome coronavirus-2 (SARS-CoV-2) is identified from Wuhan, China, and has spread almost worldwide. Recently, the newly identified SARS-CoV-2 has been confirmed to kill millions of people worldwide and is dangerous to society health, survival, and livelihood. The people with cardiovascular problems are noticed as most common patients of coronavirus disease 2019 (COVID-19). There is a greater risk of mortality and morbidity in these patients than other patients of COVID-19. In the heart, expressed angiotensin-converting enzyme 2 (ACE2) and response effect of hyperactivity with angiotensin II associated to the renin-angiotensin mechanism are key factors of hypertension, atherosclerosis, and congestive heart failure.

Recent Findings Mortality rates have been observed about $10.5 \%$ cases in patients with cardiovascular disease; however, a mortality rate of $52 \%$ was recorded in patients with heart failure, while $12 \%$ recovered ultimately. The occupancy of intense injury controlled by troponin elevation was a noteworthy factor in relation to mortality. Among 187 patients infected with SARSCoV-2, about $35 \%$ were diagnosed with cardiovascular disease (CVD) history and $28 \%$ with raised troponin. Troponin elevation was identified more frequently $(55 \%)$ in patients with cardiovascular diseases. Mortality rate in patients without cardiovascular diseases and normal troponin was 7.6\%, normal troponin and cardiovascular disease with 13.3\%, augmented troponin and without cardiovascular disease $37.5 \%$, however $69.4 \%$ among cardiovascular disease and advanced troponin.

Summary The study reflected a significant association of case fatality rate (CFR) to COVID-19 patients with cardiovascular diseases which supposed to be the most common dangerous risk factor and health challenge during the current pandemic situation.
\end{abstract}

Keywords COVID-19 $\cdot$ SARS-CoV-2 $\cdot$ Case fatality rate $\cdot$ Cardiovascular disease $\cdot$ Heart failure $\cdot$ Myocardial infarction

\section{Introduction}

Severe acute respiratory syndrome coronavirus-2 (SARS$\mathrm{CoV}-2$ ) is a member of RNA family beta human coronavirus

This article is part of the Topical Collection on Covid-19

Sushil Kumar Upadhyay

upadhyay.k.sushil@gmail.com

1 Department of Biotechnology, I.K. Gujral Punjab Technical University Jalandhar, Kapurthala, Punjab, India

2 University Institute of Biotechnology, Chandigarh University, Mohali, Punjab, India

3 Department of Biotechnology, Maharishi Markandeshwar (Deemed to be University), Mullana-Ambala, Haryana 133207, India identified in Wuhan City, China. The case of COVID-19 (coronavirus disease 2019) was first admitted in a center on 12 December 2019, and the primary phase of patients was first recognized on 6 January 2020. Even the human-tohuman transmission was viewed in mid-January 2020 [1]. The occurrences of $3 \mathrm{rd}$ and 4th stages of transmission have been accounted since 4 February 2020 [2]. In Wuhan, China has uncovered a scene of atypical pneumonia achieved by SARS-CoV-2 [3, 4]. Since December 2019, contamination has transmitted the nation over and universally $[1,5]$. The European Center for Ailment Prevention and Control showed that, beginning on 2 March 2020, more than 89,000 COVID-19 cases have been accounted all around the world, from all zones of China and 66 countries globally [3]. These beta coronaviruses belong to seven species and caused infections in humans. In the four types of 
coronavirus, predominant symptoms such as little bit phlegm are observed, but in SARS (severe acute respiratory syndrome), MERS (Middle East respiratory syndrome), and COVID-19, symptoms result in potentially fatal illnesses. Cardiometabolic request related with fundamental contamination combined with hypoxia symptoms because of intense respiratory ailment may decrease myocardial oxygen request - which gracefully linked and may lead to prompt intense myocardial infarction. Expanded shear worry because of fundamental irritation just as expanded coronary blood stream can prompt intense myocardial-localized necrosis. The prothrombotic milieu made by foundational irritation further builds the hazard, i.e., coronary thrombosis and plaque break. Due to complete illness, the electrolyte can be imbalanced and may lead to precipitation of arrhythmias while this condition can be observed in the patients of cardiac disorder. The action of renin-angiotensin-aldosterone mechanism with COVID-19 may cause issue of hypokalemia in COVID-19 patients and vulnerability of enhanced tachyarrhythmias to swift case fatality rate and mortality [6].

\section{Cardiovascular Mechanism and SARS-CoV-2}

Although the primary target of SARS-CoV-2 is the respiratory tract for COVID-19, the cardiovascular mechanism can be involved in many other ways (Fig. 1) [7, 8]. The infection of SARS-CoV-2 is developed by the spike protein activation by angiotensin-converting enzyme 2 (ACE2) receptors in humans to the Trans-Membrane Protease Serine-2 (TMPRSS2) [9]. Angiotensin-converting enzyme catalyzes the arrangement of angiotensin II (Ang II) and accordingly plays a key job in cardiorenal guideline and circulatory strain control. The overactivity of renin-angiotensin framework contributes to the pathophysiology of hypertension and cardiovascular breakdown that is reflected in utilization of ACE inhibitors during the treatment of these conditions [10]. ACE2 is known to be profoundly communicated in the human heart and may act to restrict the movement of the reninangiotensin framework by changing over Ang II to the vasodilator Ang I-7 [11]. Moreover, ongoing creature information recommend that ACE2 can adjust heart contractility, stifle cardiovascular Ang II levels, and down-direct hypoxia-instigated support of apoptotic qualities highlighting a job for ACE2-inferred peptides in the guideline of cardiovascular capacity [12]. It was expressed that overactivity of the renin-angiotensin framework is involved in the pathophysiology of incessant cardiovascular breakdown [13]. A viral disease can intensely influence the cardiovascular framework, causing an expanded danger of intense coronary conditions, myocardial discouragement prompting cardiovascular breakdown, or arrhythmias and myocarditis/pericarditis [14]. Patients with cardiovascular malady including HF (heart failure) are especially defenseless against flu and other infective ailments of the upper and lower respiratory parcel that cause a more serious danger to them $[15,16]$. In any case, the effect of the ongoing flare-up of COVID-19 brought about by the infection SARS-CoV-2 in patients with previous cardiovascular horribleness or the danger of cardiovascular entanglements has not been widely assessed [17]. In this way, the ACE2 was exceptionally communicated in pericytes of grown-up human hearts, which showed an

Fig. 1 Cardiovascular problems in patients infected by SARS$\mathrm{CoV}-2$

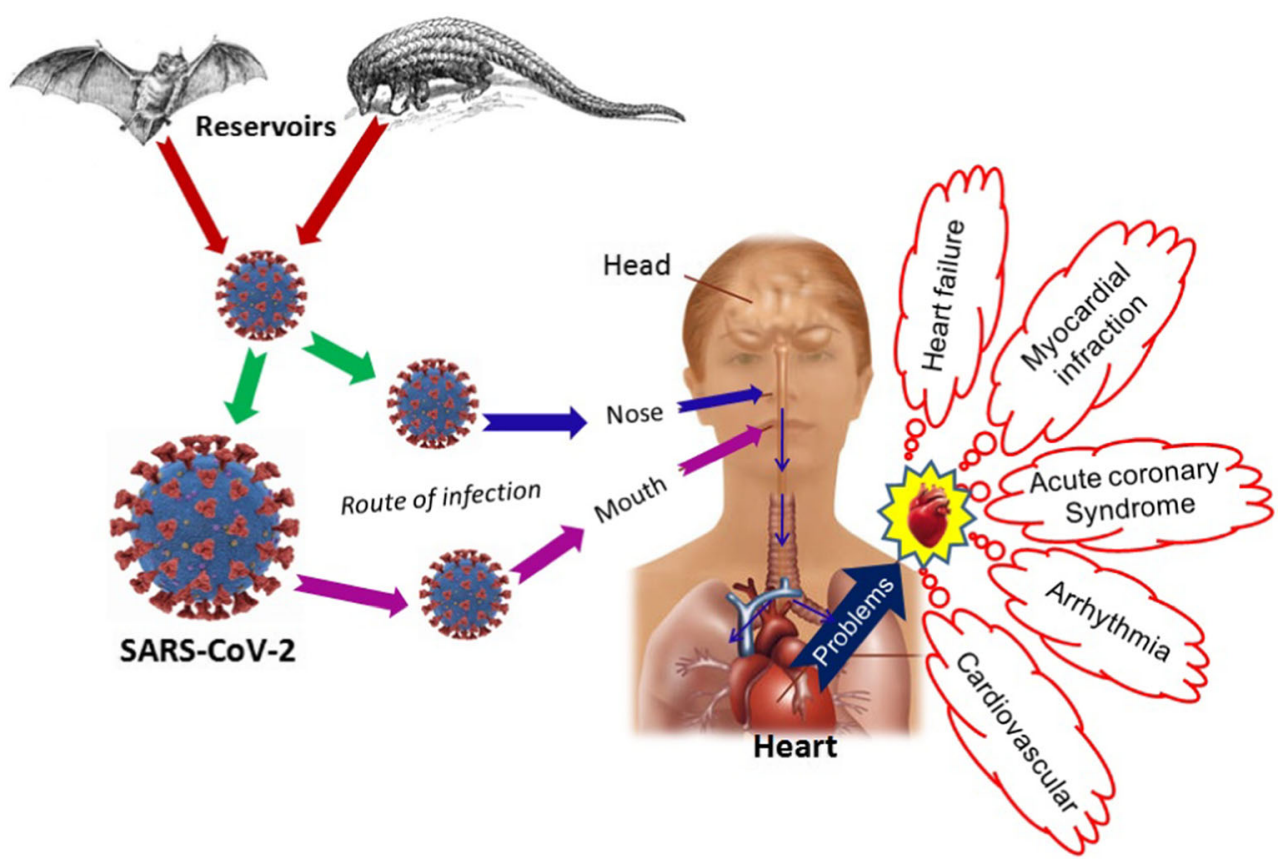


inborn helplessness of the heart to the SARS-CoV-2 disease [18]. Patients with essential cardiovascular breakdown illness showed expanded articulation of ACE2 and might have a high chance of coronary episode, advancing to extreme condition after contamination [19].

In the lung, mainly type II alveolar cells expressed angiotensin-converting enzyme 2 and the main portal of entry appears [20]. In the heart, expressed angiotensinconverting enzyme 2 and response effect of hyperactivity with angiotensin II associated to the renin-angiotensin mechanism are key factors of hypertension, atherosclerosis, and congestive heart failure [21]. Notwithstanding the lungs and heart, angiotensin-converting enzyme 2 is communicated in the intestinal epithelium, vascular endothelium, and kidneys, giving a mechanism to the multi-organ dysfunction that can be seen along with SARS-CoV-2 contamination [21, 22]. The morbidity and mortality rate is increased with increasing evidence linking COVID-19 to heart disease and leads to injury in the lung, arrhythmia, and myocardial infarction $[7,8]$. The consecutive inflammations and highly extreme types of SARS-CoV-2 are portrayed by acute routinely inflammatory reaction and the storm of cytokine, followed by multiple organ injury and also led to numbers of diseases. In patients with extreme/basic SARS-CoV-2 have investigated and indicated more circulatory degrees of cytokines in proinflammatory conditions [23, 24]. SARS-CoV-2 has been revealed a couple of months ago, and it is too soon to anticipate the drawn-out result of patients recouping from the illness. In any case, some significant messages may be brightened by past encounters with SARS because of SARS-CoV, which imparts impressive similitude to COVID-19 [25, 26]. It was accounted that among patients recovering from SARS, $68 \%$ kept on having lipid metabolism (digestion) variations from the norm at 12-year development; cardiovascular anomalies were available in $40 \%$ and glucose digestion changes in 60\% [27]. Comparable discoveries have additionally been accounted in patients recuperating from other respiratory diseases [28]. In view of this, careful adherence to those recuperating from current COVID-19 will likewise be critical to comprehend the drawn-out impacts of the illness and to shield these patients from future cardiovascular diseases (CVD). In myocardial infarction, increased cardiac troponin or electrocardiographic abnormalities were present in $7.2 \%$ in a study [29], while other studies have shown elevated cardiac biomarker as $20 \%$ [30]. The current study has basically focused on the complications due to COVID-19 in the cardiovascular patients. Data has been illustrated in this manuscript for correlation between COVID-19 and cardiovascular disorder, i.e., heart failure, myocardial breakdown, and arrhythmia. Also, the effect of SARS-CoV-2 has been observed highly in cardiovascular disease patients rather than in the patients with other pre-existing disorders.

\section{Viability of SARS-CoV-2 and Symptoms}

SARS-CoV-2 spreads prevalently through respiratory aerosolized beads and oral droplets and additionally can be recognized in the stool [31]. Transmission may happen from both symptomatic and asymptomatic patients, with auxiliary contamination rates extending $0.5-5 \%$ [32]. The SARS-CoV-2 has been shown to stay stable for $3 \mathrm{~h}$ in the aerosolized structure, as long as 1 day on cartoon and upwards of $72 \mathrm{~h}$ on plastic sheets, treated metals, and steels [33]. The median incubation time ranged between 4 and 5 days, extended to 14 days, and the $97.5 \%$ participation indication was noticed within $276 \mathrm{~h}$ of exposure $[34,35]$. The most common indications of SARS-CoV-2 are normal pyrexia and mild fatigue; however, critical symptoms are like severe fatigue, pneumonia, and multiple organ and cardiovascular issues (Table 1) $[21,32,36]$. The case mortality rate was $6 \%$ among COVID19 patients with hypertension, $7.3 \%$ with diabetes, and $10.5 \%$ with CVD, but the total cases are $2.3 \%$ [37].

\section{Incidence of SARS-CoV-2 with CVD}

The significant data of case fatality rate (CFR) around the world perspective to coronavirus, SARS, and MERS are summarized in Table $2[29,38,39]$. The data reported on 21 March 2020 showed that the case fatality rate varies greatly by country to country, geographical locations, age, and sex of patients (Table 3) [30]. The relations between total cases of COVID-19 on 12 May 2020 with case fatality rate and 21 March 2020 worked out (Table 4). The case fatality rate exponentially increases with age (Table 5 and Fig. 2) and severity of the diseases stated in a report from China (Table 6) [40]. There is an increased vulnerability in patients of SARS-CoV2 with a previous history of cardiovascular disease and allied more severe diseases leading to worse clinical outcomes [7, 23, 41, 42]. Different CVD chance factors likewise unfavorably influence the sickness of these patients, in spite of the fact that they do not improve the probability of building up a contamination.

In China, the 1527 patients of SARS-CoV-2 were assessed and of them, 9.7\% revealed pervasiveness of diabetes, $16.4 \%$ of cardio-cerebrovascular malady, and $17.1 \%$ of hypertension [7]. In spite of the fact that the commonness of hypertension as well as diabetes in this companion was like everyone of China, the pervasiveness of cardio-cerebrovascular sickness was a lot higher. The Chinese Center for Disease Control and Prevention depicted the colossal report of clinical results in 44,672 affirmed instances of COVID-19 and 6\% of hypertension, $7.3 \%$ of diabetes, and $10.5 \%$ of CVD, but the overall cases are $2.3 \%$ which was the case fatality rate [42]. However, data are lacking for different geographic locations that can vary the outcome of clinical effects and prevalence of different 
Table 1 COVID-19's symptoms with cases in China

\begin{tabular}{|c|c|c|c|c|}
\hline Symptoms & Sub-symptoms & Infra-symptoms & Range (\%) & Ref. \\
\hline \multirow[t]{9}{*}{ Most common } & Normal fever & & 87.9 & {$[32]$} \\
\hline & Production of spit & & 33.4 & [32] \\
\hline & Difficulty breathing & & 18.6 & {$[32]$} \\
\hline & Pharyngitis & & 13.9 & [32] \\
\hline & Cough (Dry) & & 67.7 & [36] \\
\hline & Fatigue & & 38.1 & [32] \\
\hline & Rhinorrhea & & 4.8 & [36] \\
\hline & \multirow[t]{2}{*}{ Gastro-intestinal problems } & Emesis/nausea & 5 & [36] \\
\hline & & Diarrhea & $4-14$ & [36] \\
\hline Mild & No pneumonia/mild pneumonia & & 81 & [21] \\
\hline \multirow[t]{3}{*}{ Severe } & Dyspnea (respiratory rate $\geq 30 / \mathrm{min}$ ) & & 14 & [21] \\
\hline & Saturation blood oxygen & & $\leq 93$ & [21] \\
\hline & Arterial oxygen partial pressure $<300$ for fraction of induced oxygen ratio & Incubation time is 24 to $48 \mathrm{~h}$ & $>50$ & [21] \\
\hline Delicate & Failure in respiratory, multiple organ dysfunction or failure & & 5 & [21] \\
\hline
\end{tabular}

cardiovascular comorbidities. Outside Hubei Province and different states of China, in Asian countries, the CFR is recorded lower, but in some European countries and the USA including Washington, it is much higher [27, 40]. The comorbidities were typical in this associate, congestive cardiovascular breakdown in $42.9 \%$ cases. In $33.3 \%$ of patients, intense cardiovascular brokenness occurred and approximately $52.4 \%$ patients died. However except certain extreme cases, in general case fatality rate in the United States is by all accounts a lot of lower i.e. 201 passing out of 15,219 affirmed cases [42]. Despite the fact, it is probably going to ascend the same numbers of patients as of now hospitalized and have not yet had the unmistakable result $[27,28]$. So, the cardiovascular problems in SARS-CoV-2 are mainly acute cardiac injury, heart failure, arrhythmia, and potential long-term consequences (Fig. 3) [12, 43].

\section{Myocardial Infarction and SARS-CoV-2}

Various informational indexes now confirm the expanded hazard for bleak and mortal entanglements due to COVID19 among individuals with previous cardiovascular malady history including hypertension, coronary course infection, and heart failure [44]. These striking perceptions have strengthened preventive strategies and without a doubt have brought about its spared. In spite of the fact, scenes of clinical myocarditis have been suspected and a couple of cases have been accounted in earlier investigations of three heart associations as the SARS-CoV-2 has been hard to affirm [45]. Acute myocardial (coronary) infarction is usually portrayed as cardiovascular complexity in SARS-CoV-2. Various data have utilized several explanations for acute myocardial infarction, remembering ascends for cardiovascular catalyses or potentially electrocardiographic variations from the norm. As high as it may be, the elevation of high-efficacy cardiac troponin-I above the 99th percentile top remarked range is the most commonly used definition. The general recurrence of cardiovascular infarction has been variable, yet roughly positive cases are $8-12 \%$ which is known to make critical tallness of cardiac troponin-I [30]. The recently referenced assessment of the China's population examinations uncovered $8 \%$ recurrence of extraordinary cardiovascular infarction in patients with reasonable outcome at $17 \%$ rate of cardiac troponin-I rise [7, 22]. In spite of the certifiable rate, acute cardiovascular infarction has been dependably exhibited a solid negative disease marker in patients of COVID-19 [23, 41]. Patients with ICU or serious/lethal sickness are bound to have some wrinkle of

Table 2 Case fatality rate in significantly different pandemic around the world

\begin{tabular}{lrr}
\hline Types & Range (\%) & Ref. \\
\hline China's original reports suggested CRF & {$[37]$} \\
Fatal risk of symptomatic case (likely to die after developing symptoms) was estimated with subsequent reports & 2.3 & 1.4 \\
Contrasts with influenza & 0.1 & 34 \\
MERS & {$[33]$} \\
SARS & {$[33]$} \\
\hline
\end{tabular}


Table 3 Based on data reported from 21 March 2020, the CFR varies greatly by country

\begin{tabular}{llll}
\hline Country & Cases $(\%)$ & Number of cases & Reference \\
\hline China & 4.0 & 81,304 & {$[35]$} \\
Italy & 0.6 & 47,021 & {$[35]$} \\
Iran & 7.5 & 20,610 & {$[35]$} \\
Spain & 5.4 & 25,374 & {$[35]$} \\
South Korea & 1.2 & 8779 & {$[35]$} \\
Germany & 0.3 & 21,828 & {$[35]$} \\
USA & 1.3 & 22,043 & {$[35]$} \\
\hline
\end{tabular}

troponin rise. On the other hand, recurrence of raised cardiac troponin is lower (only 1-2\%) in patients with kind-hearted malady who do not require intensive care unit (ICU) affirmation. Intense heart injury can happen in any of the systems depicted above, and there might be an expansion in cardiovascular troponin in SARS-CoV-2 patients. The general occupation of different components has not been delineated anyway prompt myocardial infarction (for instance non-coronary) because of an inflammatory disease of the heart muscle (myocardium), i.e., myocarditis. During an episode of Toronto SARS, the observations maintained by a past assessment move patients killed due to myocarditis association [46]. Just a single Chinese investigation revealed the rate of cardiovascular breakdown in the patients of SARS-CoV-2 [22]. The $52 \%$ of patients were suffering from cardiovascular breakdown and thusly died; however, $12 \%$ patients released from the hospital or clinic. Evidence of hospitalized patients for SARS-CoV-2 is normal in myocardial infarction; however, the reasons for myocardial infarction have not been elucidated, and its contribution to the occurrence of heart failure is not well characterized.

The recurrence of hospitalized patients with COVID-19 is different among myocardial infarction as reflected by height in troponin levels with revealed frequencies 7-28\% [33-35]. A few investigations have distinguished more prominent recurrence and size of troponin elevations in hospitalized patients with extreme ailment and more awful results [41].

Table 4 Relation between total cases of COVID-19 on 12 May 2020 with CFR on 21 March 2020

\begin{tabular}{lll}
\hline Country & CFR on 21 March 2020 & Total cases on 12 May 2020 \\
\hline China & 81,304 & 82,920 \\
Italy & 47,021 & 222,618 \\
Iran & 20,610 & 112,248 \\
Spain & 25,374 & 270,897 \\
South Korea & 8779 & 10,963 \\
Germany & 21,828 & 173,766 \\
USA & 22,043 & $1,431,438$ \\
\hline
\end{tabular}

Table 5 CFR exponentially increases with age (China's report)

\begin{tabular}{lll}
\hline Ages & CFR in \% & Reference \\
\hline $0-50$ years old & $<1$ & {$[37]$} \\
$50-59$ years old & 1.3 & {$[37]$} \\
60-69 years old & 3.6 & {$[37]$} \\
$70-79$ years old (septuagenarians) & 8 & {$[37]$} \\
$80-89$ years old (octogenarians) & 14.8 & {$[37]$} \\
\hline
\end{tabular}

Information is missing on the recurrence of troponin heights in asymptomatic or just mildly symptomatic COVID-19 patients. About $19.7 \%$ of the COVID-19 patients who have high-sensitivity troponin-I were admitted to a hospital in Wuhan, China [47]. Patients with this scar of myocardial infarction were more established and had more comorbidities including chronic heart failure in $14.6 \%$ versus $1.5 \%$ and greater laboratory abnormalities like higher levels of aspartate aminotransferase, procalcitonin, and C-reactive protein and also more lung radiographic abnormalities, and more complications compared with those without myocardial infarction [47]. The mortality rate was also higher with myocardial infarction $(51.2 \%$ vs. $4.5 \%)$ [48]. The risk of death at symptom onset was four times higher in patients with evidence of myocardial infarction at admission.

The other study in Wuhan showed that elevations in high-sensitivity troponin-I and more than 99th percentile top remarked limit threshold were identified upon admission in $46 \%$ non-survivors versus $1 \%$ survivors [22]. In contrast, a study of 24 critically ill COVID-19 patients in Seattle found elevated troponin levels after intensive care unit admission in only $13(15 \%)$ of tested patients, with $50 \%$ mortality rate [49]. Some differences in the frequency of troponin augmentation may be due to the use of different troponin assays and differences in patient populations. Only one study was assessed and found that the patients with proof of myocardial infarction have a greater spreading of heart disease and cardiovascular risks compared with hypertensive biomarkers [47]. In this way, it is not yet conceivable to decide if myocardial infarction is an independent risk marker in COVID-19 or if the hazard related with it is identified to the weight of previous cardiovascular sickness.

\section{Heart Failure and COVID-19}

Restricted information is accessible on the frequency of SARS-CoV-2 with pre-existing heart failure patients. In a review report on 799 hospitalized COVID-19 patients in Wuhan, China, with pre-existing heart failure, it was reflected that $49 \%$ patients died, $3 \%$ patients recuperated, and $1 \%$ pattern predominance of constant chronic heart failure in the 
Table 6 CFR increases with the severity of the diseases (China's report)

\begin{tabular}{llll}
\hline COVID-19 symptoms & Disease symptoms & CFR (\%) & Ref. \\
\hline Mild or severe cases & - & No death & {$[37]$} \\
Critical patients & - & 49 & {$[37]$} \\
Patients with no comorbidities & - & 0.9 & 10.5 \\
Patients with medical comorbidities & Cardiovascular disease (CVD) & 9.2 & 6.3 \\
& Diabetes mellitus (DM) & 6 & {$[37]$} \\
& Chronic obstructive pulmonary disease & {$[37]$} \\
& Hypertension & [37] & [37] \\
& Cancer & [32] & [32] \\
\hline
\end{tabular}

combined groups [50]. In an investigation of 191 patients hospitalized in two different medical centers in Wuhan, heart failure was recognized in patients who died, i.e., $52 \%$, and who recuperated, i.e., $12 \%$ patients [22]. The occurrence of acute heart failure was not archived in some arrangement of hospitalized COVID-19 patients and raised natriuretic peptide has been identified, especially in patients with proof of heart injury. In the above-mentioned series of 416 hospitalized patients, NT-proBNP levels were significantly lesser in patients without elevated troponin ranges than in patients with troponin elevation (139 vs. $1689 \mathrm{pg} / \mathrm{ml}$ ) [47].

Cardiovascular-related diseases and its risk factors are exceptionally common in SARS-CoV-2 hospitalized patients [7]. For instance, in a data of 191 patients hospitalized in Wuhan, comorbidities included $30 \%$ hypertension, diabetes mellitus in $19 \%$, and coronary heart disease in $8 \%$ [22]. Patients with a known history of heart failure may have an acute decompensation due to the development of COVID-19 disease [51]. Particularly the prevalence of cardiovascular diseases and heart disease in general varies from population to population $[22,41]$. Thus, in patients diagnosed with COVID-19 diagnosed, there is a broad category for prevalent cardiovascular diseases. Rates have been reported between 4.2 and $25 \%$, with most of China's $[50,52]$ range. The percentage is higher among patients admitted to intensive care units or who died [50]. In one

Fig. 2 Trends of case fatality rate and its correlation to age of patients (Source: China's report) investigation, $22.7 \%$ of all fatal case patients participate with preliminary cardiac and heart-related diseases, and the case fatality rate was $10.5 \%$ [53]. The jobs of ACE2 articulation in SARS-CoV-2 pathogenesis and human COVID-19 helplessness are to a great extent obscure. Since SARSCoV-2 uses ACE2 as the receptor, it is intelligent to expect that every single human cell that expresses ACE2 are the likely focuses for SARSCoV-2 [54]. In this way, the accompanying inquiries with respect to ACE2 articulation comparable to COVID-19 defenselessness can be asked [55, 56]: (a) Which parts of the body express ACE2? (b) Which ACE2-communicating organs are inclined to SARS-CoV-2 contamination? (c) Is higher articulation level of ACE2 equivalent to more prominent COVID-19 helplessness?

\section{Case Fatality Rate and COVID-19 Patients With Cardiovascular Disease}

There is considerable proof of a relationship between cardiovascular disease hazard variables of hypertension, diabetes, cardiovascular diseases, and the hazard and seriousness of COVID-19 contamination [52, 57]. The accompanying observational investigations represent the greatness of the relationship [40,58]. There are 169 emergency

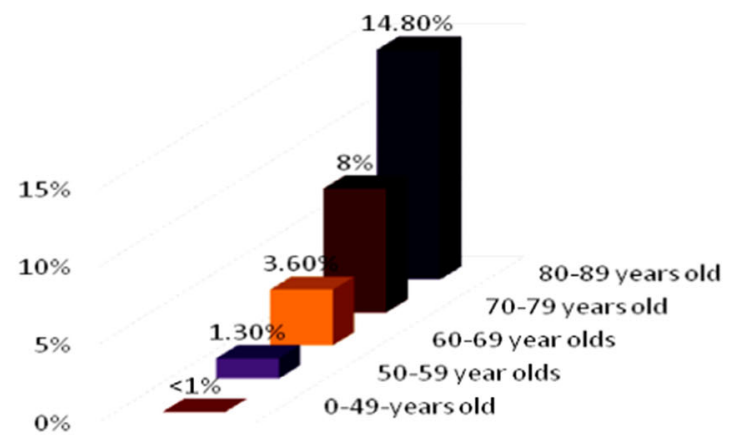


Fig. 3 Cardiovascular problems in COVID-19 patients
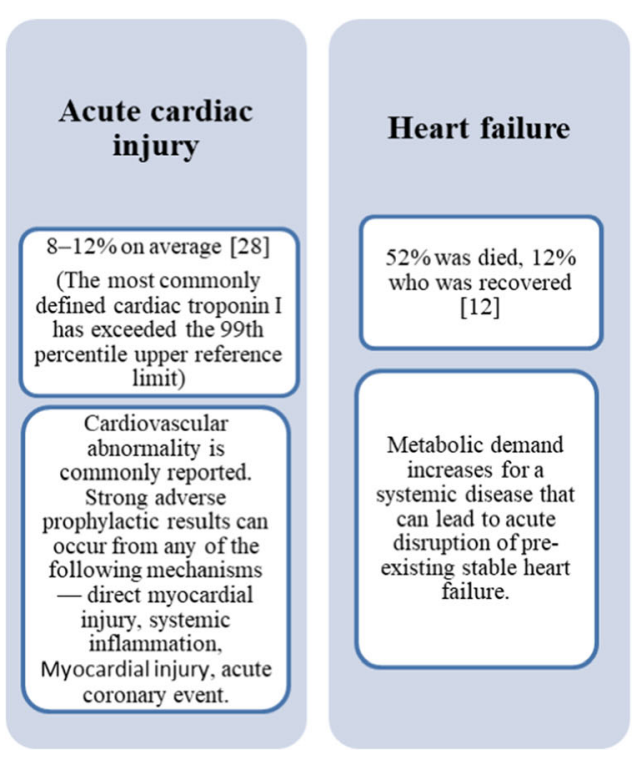

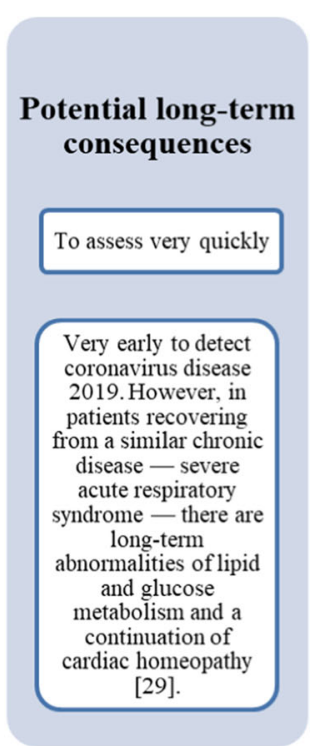

clinics in Asia, Europe, and North America by using inspection database from the correlation between standard cardiac and heart-related diseases, and hospital deaths were assessed among patients hospitalized with SARS-CoV-2 [59]. Out of total 8910 COVID-19 patients, $94.21 \%$, i.e., 8395 patients, survived and were discharged, and $5.78 \%$, i.e., 515 patients, died in the hospital. Baseline cardiovascular diseases comparative with no contamination were autonomously connected with an expanded danger in hospital (medical clinic) demise ( $10.2 \%$ vs. $5.2 \%$; chance proportion 2.70; 95\%; cardiac infraction, CI 2.08-3.51\%). The Chinese Center for Disease Control and Prevention reported on 11 February 2020 that about 72,314 cases and 44,672 active cases were confirmed and the crude mortality rate recorded was $2.3 \%$ [60]. For those octogenarians (a person who is between 80 and 89 years old) or above ages, the case fatality rate was $14.8 \%[26,60]$. History of coronary and heart diseases was available in $4.2 \%$ everything being equal, however in $22.7 \%$ of lethal cases. The case fatality rate among patients with coronary and heart diseases was 10.5\%. Another report assessed 1099 cases from 30 territories inside terrain China [34]. Among them, $15.7 \%$ were classified as severe illness and a primary endpoint, while $6.1 \%$ defined as dead or intensive care unit admission with mechanical ventilation. The presence of coronary heart diseases (non-critical disease vs. critical, i.e., $1.8 \%$ vs. $5.8 \%$, and primary endpoint vs. no primary endpoint, i.e., $9 \%$ vs. $2 \%$ ) was consistently higher between patients with critical illness versus non-critical illness and patients with primary endpoint versus primary endpoint. The 191 patients from Wuhan Province diagnosed before 31 January 2020 showed significant inseparable associations with the outcome of death for coronary heart diseases $(24 \%$ vs. $1 \%$, $p<0.0001)[12]$.
Another study found that the occupancy of intense injury controlled by troponin elevation was a noteworthy factor in the relation of cardiovascular disease mortality [61]. Among the 187 patients infected with SARS-CoV-2, 66 (35\%) had cardiovascular diseases (marked as coronary heart diseases, hypertension, or cardiomyopathy) in background, and troponin was raised in $52(28 \%)$ patients. Troponin elevation was identified as more frequent in patients with cardiovascular diseases $(55 \%$, i.e., 36 of 66$)$. The mortality rate in patients with chronic kidney disease and elevated troponin was $69 \%$ (i.e., 25 of 36). Mortality rate in patients without cardiovascular diseases and normal troponin was $7.6 \%$, normal troponin and cardiovascular disease with $13.3 \%$, advanced troponin and without cardiovascular disease with $37.5 \%$, and $69.4 \%$ between cardiovascular diseases and advanced troponin (Table 7) [28]. Moreover, troponin elevation corresponded with rises in C-responsive protein, and higher troponin raises anticipated higher mortality. Although interpretation is included in the number of patients, there is a suggestion that patients with underlying cardiovascular diseases (including hypertension) have an increased risk of acute injury and worsening survival in the event of injury. The reason for this relationship and whether injury increases the risk for myocardial infractions or myocarditis will require additional investigation. COVID-19 is the pandemic disease globally and currently it has led to death of several people across worldwide [62]. The most patients affected with this disease are of cardiovascular obligations, which include heart failure, myocardial breakdown, and arrhythmia. It has been observed that the patients with pre-cardiovascular disease develop new cardiac disorders in the patients affected with SARS CoV-2 [62]. Further research as well as clinical trials is going on for the study of mechanism, effect, and treatment of COVID-19, also for combating the effect of SARS-CoV-2 in patients with cardiovascular diseases. 
Table 7 Mortality rate in patients with CVD and troponin

CVD with troponin

Mortality rate (\%)

Without cardiovascular diseases and normal troponin

With normal troponin and cardiovascular disease

13.3

Without advanced troponin and cardiovascular disease

37.5

With advanced troponin and cardiovascular diseases

69.4

\section{Conclusions}

SARS-CoV-2 is spreading prevalently through respiratory beads, yet in addition can be aerosolized or recognized in the stool. Transmission may happen from both symptomatic and asymptomatic patients, with auxiliary contamination rates extending $0.5-5 \%$. The case fatality rate was $6 \%$ of hypertension, $7.3 \%$ of diabetes, and the $10.5 \%$ of cardiovascular diseases, but the overall cases were $2.3 \%$. The mortality rates in an investigation of 191 patients hospitalized in two different medical centers in Wuhan were recorded as $52 \%$ associated to heart failure; however, $12 \%$ recovered and came back to home. Another study found that the occupancy of intense injury controlled by troponin elevation was a noteworthy factor in the relation of cardiovascular disease mortality. The 187 patients infected by SARS-CoV-2 showed $35 \%$ cardiovascular disease backgrounds, and $28 \%$ with raised troponin. Troponin elevation was identified as more frequent in patients with cardiovascular diseases, i.e., 55\%. Mortality rate in patients without cardiovascular diseases and normal troponin was recorded as 7.6\%, normal troponin and cardiovascular disease with $13.3 \%$, advanced troponin and without cardiovascular disease with $37.5 \%$, and $69.4 \%$ among cardiovascular disease with raised troponin situation. We can conclude that the effect of SARS-CoV-2 in cardiovascular disease patients is dangerous and the most common risk factor and health challenge for up to septuagenarians and octogenarians in the current pandemic situation.

Acknowledgments The authors would like to acknowledge the facilities provided by M.M. (Deemed to be University) Mullana-Ambala (HR), India, for carrying out this interuniversity collaborative research work.

\section{Compliance with Ethical Standards}

Conflict of Interest None

Human and Animal Rights and Informed Consent This article does not contain any studies with human or animal subjects performed by any of the authors.

\section{References}

1. Dan S, Sharma D, Mandal M, Sharma D. Incidence of COVID-19 and its correlation between temperature and population density. Int
J Sci Res Biol Sci. 2020;7(2):134-41. https://doi.org/10.26438/ ijsrbs/v7i2.134141.

2. Phelan AL, Katz R, Gostin LO. The novel coronavirus originating in Wuhan, China: challenges for global health governance. J Am Med Assoc. 2020;323:709-10. https://doi.org/10.1001/jama.2020. 1097.

3. Wu F, Zhao S, Yu B, Chen YM, Wang W, Song ZG, et al. A new coronavirus associated with human respiratory disease in China. Nature. 2020;579(7798):265-9. https://doi.org/10.1038/s41586020-2008-3.

4. Zhou P, Yang XL, Wang XG, Hu B, Zhang L, Zhang W, et al. A pneumonia outbreak associated with a new coronavirus of probable bat origin. Nature. 2020;579(7798):270-3. https://doi.org/10.1038/ s41586-020-2012-7.

5. Ewen C. Time to use the p-word? Coronavirus enters dangerous new phase. Nature. 2020. https://doi.org/10.1038/d41586-02000551-1.

6. Chen D, Li X, Song Q, Hu C, Su F, Dai J. Hypokalemia and clinical implications in patients with coronavirus disease 2019 (COVID19). Med Rxiv. 2020. https://doi.org/10.1101/2020.02.27. 20028530.

7. Xiong TY, Redwood S, Prendergast B, Chen M. Coronaviruses and the cardiovascular system: acute and long-term implications. Eur Heart J. 2020;41:1798-800. https://doi.org/10.1093/eurheartj/ ehaa231.

8. Li B, Yang J, Zhao F, Zhi L, Wang X, Liu L, et al. Prevalence and impact of cardiovascular metabolic diseases on COVID-19 in China. Clin Res Cardiol. 2020;109(5):531-8. https://doi.org/10. 1007/s00392-020-01626-9.

9. Hoffmann M, Kleine-Weber H, Schroeder S, Krüger N, Herrler $\mathrm{T}$, Erichsen $\mathrm{S}$, et al. SARS-CoV-2 cell entry depends on ACE2 and TMPRSS2 and is blocked by a clinically proven protease inhibitor. Cell. 2020;181(2):271-80. https://doi.org/10.1016/j. cell.2020.02.052.

10. Goulter AB, Goddard MJ, Allen JC, Clark KL. ACE2 gene expression is up-regulated in the human failing heart. BioMed Central Med. 2004;2:19. https://doi.org/10.1186/1741-7015-2-19.

11. Oudit GY, Crackower MA, Backx PH, Penninger JM. The role of ACE2 in cardiovascular physiology. Trends Cardiovasc Med. 2003;13:93-101. https://doi.org/10.1016/s1050-1738(02)00233-5.

12. Crackower MA, Sarao R, Oudit GY, Yagil C, Kozieradzki I, Scanga SE, et al. Angiotensin-converting enzyme 2 is an essential regulator of heart function. Nature. 2002;417:822-8. https://doi. org/10.1038/nature00786.

13. Chhabra KH, Chodavarapu H, Lazartigues E. Angiotensin converting enzyme 2: a new important player in the regulation of glycemia. Int Union Biochem Mol Biol. 2013;65(9):731-8. https:// doi.org/10.1002/iub.1190.

14. Faconti L, Chowienczyk PJ, Shah AM. Cardiovascular disease, heart failure and COVID-19. J Renin-Angiotensin-Aldosterone Syst. 2020:1-3. https://doi.org/10.1177/1470320320926903.

15. Udell JA, Zawi R, Bhatt DL, Keshtkar-Jahromi M, Gaughran F, Phromminikul A, et al. Association between influenza vaccination and cardiovascular outcomes in highrisk patients: a meta-analysis. J 
Am Med Assoc. 2013;310:1711-20. https://doi.org/10.1001/jama. 2013.279206.

16. Corrales-Medina VF, Musher DM, Shachkina S, Chirionos JA. Acute pneumonia and the cardiovascular system. Lancet. 2013;381(9865):496-505. https://doi.org/10.1016/S01406736(12)61266-5.

17. Zhou F, Yu T, Du R, Fan G, Liu Y, Liu Z, et al. Clinical course and risk factors for mortality of adult in patients with COVID-19 in Wuhan, China: a retrospective cohort study. Lancet. 2020;736:19. https://doi.org/10.1016/S0140-6736(20)30566-3.

18. Chen L, Li X, Chen M, Feng Y, Xiong C. The ACE2 expression in human heart indicates new potential mechanism of heart injury among patients infected with SARS-CoV-2. Cardiovasc Res. 2020;116:1097-100. https://doi.org/10.1093/cvr/cvaa078.

19. Yancy CW, Fonarow GC. Coronavirus disease 2019 (COVID-19) and the heart: is heart failure the next chapter? J Am Med Asso Cardiol. 2020. https://doi.org/10.1001/jamacardio.2020.3575.

20. Zhao Y, Zhao Z, Wang Y, Zhou Y, Ma Y, Zuo W. Single-cell RNA expression profiling of ACE2, the putative receptor of Wuhan 2019-nCov. Bio Rxiv. 2020. https://doi.org/10.1101/ 2020.01.26.919985.

21. Tikellis C, Thomas MC. Angiotensin-converting enzyme 2 (ACE2) is a key modulator of the renin angiotensin system in health and disease. Int J Pept. 2012;2012:1-8. https://doi.org/10. $1155 / 2012 / 256294$

22. Zhang H, Penninger JM, Li Y, Zhong N, Slutsky AS. Angiotensin-converting enzyme 2 (ACE2) as a SARS-CoV-2 receptor: molecular mechanisms and potential therapeutic target. Intensive Care Med. 2020;46:586-90. https://doi.org/10. 1007/s00134-020-05985-9.

23. Zhou F, Yu T, Du R, Fan G, Liu Y, Liu Z, et al. Clinical course and risk factors for mortality of adult in patients with COVID-19 in Wuhan, China: retrospective cohort study. Lancet. 2020;395(10229):1054-62. https://doi.org/10.1016/S01406736(20)30566-3.

24. Huang C, Wang Y, Li X, Ren L, Zhao J, Hu Y, et al. Clinical features of patients infected with 2019 novel coronavirus in Wuhan, China. Lancet. 2020;395(10223):497-506. https://doi. org/10.1016/S0140-6736(20)30183-5.

25. Sood S, Aggarwal V, Aggarwal D, Upadhyay SK, Sak K, Tuli HS, et al. Covid-19 pandemic: from molecular biology, pathogenesis, detection and treatment to global societal impact. Curr Pharma Rep. 2020. https://doi.org/10.1007/s40495-020-00229-2.

26. Upadhyay SK, Singh R, Singh M, Kumar V, Yadav M, Aggarwal $\mathrm{D}$, et al. COVID-19 in republic of India: a report on situation and precautionary strategies to global pandemic. Bull Environ Pharmacol Life Sci. 2020;9(6):39-48.

27. World Health Organization. Coronavirus disease 2019 (COVID19) situation report-61. 2020. https://www.who.int/docs/defaultsource/coronaviruse/situationreports/20200321-sitrep-61-covid-19. pdf? sfvrsn=ce5ca11c 2 .

28. Guo T, Fan Y, Chen $\bar{M}, \mathrm{Wu} X$, Zhang L, He T, et al. Cardiovascular implications of fatal outcomes of patients with coronavirus disease 2019 (COVID-19). J Am Med Asso Cardiol. 2020;5:811. https:// doi.org/10.1001/jamacardio.2020.1017.

29. Wu JT, Leung K, Bushman M, Kishore N, Niehus R, de Salazar PM, et al. Estimating clinical severity of COVID-19 from the transmission dynamics in Wuhan, China. Nat Med. 2020;26:506-10. https://doi.org/10.1038/s41591-020-0822-7.

30. Lippi G, Plebani M. Laboratory abnormalities in patients with COVID-2019 infection. Clin Chem Lab Med. 2020;58:1131-4. https://doi.org/10.1515/cclm-2020-0198.

31. Zou L, Ruan F, Huang M, Liang L, Huang H, Hong Z, et al. SARSCoV-2 viral load in upper respiratory specimens of infected patients. New Eng J Med. 2020;382:1177-9. https://doi.org/10. 1056/NEJMc2001737.
32. World Health Organization. Report of the WHO-China joint mission on coronavirus disease 2019 (COVID-19). 2020. https://www. who.int/publications-detail/reportof-the-who-china-joint-missionon-coronavirus-disease-2019-(covid-19).

33. van Doremalen N, Bushmaker T, Morris DH, Holbrook MG, Gamble A, Williamson BN, et al. Aerosol and surface stability of SARS-CoV-2 as compared with SARS-CoV-1. New Eng J Med. 2020;382(16):1564-7. https://doi.org/10.1056/NEJMc2004973.

34. Guan W, Ni Z, Hu Y, Liang W, Ou C, He X, et al. Clinical characteristics of coronavirus disease 2019 in China. New Eng J Med. 2020;382(18):1708-20. https://doi.org/10.1056/NEJMoa2002032.

35. Lauer SA, Grantz KH, Bi Q, Jones FK, Zheng Q, Meredith HR, et al. The incubation period of coronavirus disease 2019 (COVID19) from publicly reported confirmed cases: estimation and application. Ann Intern Med. 2020;172(9):577-8. https://doi.org/10. 7326/M20-0504.

36. Corrales-Medina VF, Alvarez KN, Weissfeld LA, Angus DC, Chirinos JA, Chang CC, et al. Association between hospitalization for pneumonia and subsequent risk of cardiovascular disease. J Am Med Assoc. 2015;313(3):264-74. https://doi.org/10.1001/jama. 2014.18229.

37. World Health Organization. Report of the WHO-China joint mission on coronavirus disease 2019 (COVID-19). 2020. https://www. who.int/docs/default-source/coronaviruse/who-china-jointmission-on-covid-19-final-report.pdf

38. Munster VJ, Koopmans M, van Doremalen N, van Riel D, de Wit E. A novel coronavirus emerging in China: key questions for impact assessment. New Eng J Med. 2020;382(8):692-4. https://doi. org/10.1056/NEJMp2000929.

39. Dong E, Du H, Gardner L. An interactive web-based dashboard to track COVID-19 in real time. Lancet Infect Dis. 2020;20(5):533-4. https://doi.org/10.1016/S1473-3099(20)30120-1.

40. Wu Z, McGoogan JM. Characteristics of and important lessons from the coronavirus disease 2019 (COVID-19) outbreak in China: summary of a report of 72314 cases from the Chinese Center for Disease Control and Prevention. J Am Med Assoc. 2020;323(13):1239-42. https://doi.org/10.1001/jama.2020.2648.

41. Wang B, Hu B, Hu C, Zhu F, Liu X, Zhang J, et al. Clinical characteristics of 138 hospitalized patients with 2019 novel coronavirus-infected pneumonia in Wuhan. China J Am Med Asso. 2020;323(11):1061-9. https://doi.org/10.1001/jama. 2020.1585 .

42. Arentz M, Yim E, Klaff L, Lokhandwala S, Riedo FX, Chong M, et al. Characteristics and outcomes of 21 critically ill patients with COVID-19 in Washington State. J Am Med Assoc. 2020;323:1612. https://doi.org/10.1001/jama.2020.4326.

43. Wu Q, Zhou L, Sun X, Yan Z, Hu C, Wu J, et al. Altered lipid metabolism in recovered SARS patients twelve years after infection. Sci Res. 2017;7:9110. https://doi.org/10.1038/s41598017-09536-z.

44. Guo T, Fan Y, Chen M, Wu X, Zhang L, He T, et al. Cardiovascular implications of fatal outcomes of patients with coronavirus disease 2019 (COVID-19). J Am Med Asso Cardiol. 2020. https://doi.org/ 10.1001/jamacardio.2020.1017.

45. Wu Z, McGoogan JM. Characteristics of and important lessons from the coronavirus disease 2019 (COVID-19) outbreak in China: summary of a report of 72314 cases from the Chinese Center for Disease Control and Prevention. J Am Med Assoc. 2020;323:1239. https://doi.org/10.1001/jama.2020.2648.

46. Oudit GY, Kassiri Z, Jiang C, Liu PP, Poutanen SM, Penninger $\mathrm{JM}$, et al. SARS-coronavirus modulation of myocardial ACE2 expression and inflammation in patients with SARS. Eur J Clin Investig. 2009;39(7):618-25. https://doi.org/10.1111/j.13652362.2009.02153.x.

47. Shi S, Qin M, Shen B, Cai Y, Liu T, Yang F, et al. Association of cardiac injury with mortality in hospitalized patients with COVID- 
19 in Wuhan, China. J Am Med Asso Cardiol. 2020;5:802. https:// doi.org/10.1001/jamacardio.2020.0950.

48. Lippi G, Lavie CJ, Sanchis-Gomar F. Cardiac troponin I in patients with coronavirus disease 2019 (COVID-19): evidence from a metaanalysis. Prog Cardiovasc Dis. 2020;63:390-1. https://doi.org/10. 1016/j.pcad.2020.03.001.

49. Bhatraju PK, Ghassemieh BJ, Nichols M, Kim R, Jerome KR, Nalla AK, et al. COVID-19 in critically ill patients the Seattle region: case series. N Engl J Med. 2020;382:2012-22. https://doi.org/ 10.1056/NEJMoa2004500.

50. Chen $\mathrm{T}, \mathrm{Wu} \mathrm{D}$, Chen $\mathrm{H}$, et al. Clinical characteristics of 113 deceased patients with coronavirus disease 2019: retrospective study. Brit Med J. 2020. https://doi.org/10.1136/bmj.m1295.

51. Fried JA, Ramasubbu K, Bhatt R, Topkara VK, Clerkin KJ, Horn $\mathrm{E}$, et al. The variety of cardiovascular presentations of COVID-19. Circulat. 2020;141:1930-6. https://doi.org/10.1161/ CIRCULATIONAHA.120.047164.

52. Madjid M, Safavi-Naeini P, Solomon SD, Vardeny O. Potential effects of coronaviruses on the cardiovascular system: a review. J Am Med Asso Cardiol. 2020;5:831. https://doi.org/10.1001/ jamacardio.2020.1286.

53. The Novel Coronavirus Pneumonia Emergency Response Epidemiology Team. The epidemiological characteristics of an outbreak of 2019 novel coronavirus diseases (COVID-19): China. China CDC Week. 2020. https://doi.org/10.3760/cma.j.issn.02546450.2020.02.003.

54. Li G, Fan Y, Lai Y, Han T, Li Z, Zhou P, et al. Coronavirus infections and immune responses. J Med Virol. 2020;92:424-32. https://doi.org/10.1002/jmv.25685.

55. Tan HW, Xu Y-M, Lau ATY. Angiotensin-converting enzyme 2: the old door for new severe acute respiratory syndrome coronavirus 2 infection. Rev Med Virol. 2020;e2122. https://doi.org/10.1002/ rmv.2122.
56. Chen Y, Liu Q, Guo D. Emerging coronaviruses: genome structure, replication, and pathogenesis. J Med Virol. 2020;92:418-23. https://doi.org/10.1002/jmv.25681.

57. Liang W, Guan W, Chen R, Wang W, Li J, Xu K, et al. Cancer patients in SARS-CoV-2 infection: a nationwide analysis in China. Lancet Oncol. 2020;21(3):335-7. https://doi.org/10.1016/S14702045(20)30096-6.

58. Epidemiology Working Group for NCIP Epidemic Response, Chinese Center for Disease Control and Prevention. The epidemiological characteristics of an outbreak of 2019 novel coronavirus diseases (COVID-19) in China. Zhonghua Liu Xing Bing Xue Za Zhi. 2020;41(2):145-51. https://doi.org/10.3760/cma.j.issn.02546450.2020.02.003.

59. Mehra MR, Desai SS, Kuy S, Henry TD, Patel AN. Cardiovascular disease, drug therapy, and mortality in Covid-19. N Engl J Med. 2020;382:e102. https://doi.org/10.1056/NEJMoa2007621.

60. Chow YW, Pietranico R, Mukerji A. Studies of oxygen binding energy to hemoglobin molecule. Biochem Biophys Res Commun. 1975;66(4):1424-31. https://doi.org/10.1016/0006291x(75)90518-5.

61. Clerkin KJ, Fried JA, Raikhelkar J, Sayer G, Griffin JM, Masoumi A, et al. Coronavirus disease 2019 (COVID-19) and cardiovascular disease. Circulat. 2020;141:1648-55. https://doi.org/10.1161/ CIRCULATIONAHA.120.046941.

62. Upadhyay SK, Singh R, Babita, Kumar G, Singh G. The outbreak and challenges of novel coronavirus (COVID-19): the global pandemic emergency of early $2 \mathrm{~K} 20$ and Indian scenario. Int J Biol Pharma All Sci. 2020;9(5):1173-99. https://doi.org/10.31032/ IJBPAS/2020/9.5.5126.

Publisher's Note Springer Nature remains neutral with regard to jurisdictional claims in published maps and institutional affiliations. 